To the Editors:

\title{
Evidence based medicine - a reply
}

The authors of the letter on evidence based medicine (EBM) should be congratulated for their bold attempt to use the concept of EBM in their clinical practice (1). However, I would like to express my concerns about certain conclusions made in that article.

They have used the finding of a meta-analysis not performed within the framework of a systematic review as "conclusive evidence' to change practice. Meta-analyses have received a mixed reception both from statisticians and clinicians throughout their history (2). There are several examples of meta-analyses of trials whose findings were later contradicted by a single large randomised trial or by a systematic review (2). Meta-analyses are liable to numerous biases both at the level of the individual trial and the dissemination of trial results (publication bias). Results from studies may appear unchallengeable, particularly those which have involved extensive searches and have combined findings using meta-analysis techniques. This aura of infallibility should be rejected; these are prepared by people and people make mistakes (3).

Assessing a research article includes critical appraisal of the validity, importance and applicability of the evidence in the article (4). Without such a comprehensive assessment it would be unwise to take the results of a single trial as 'convincing evidence' to use a drug like acyclovir which is costly and can cause serious adverse effects. We would all like our own studies to have earth-shaking significance. Thus it is not surprising that authors are not always impartial when interpreting their results. One should be more circumspect about accepting the claims of a single paper as convincing evidence.

Therefore, evidence should be carefully scrutinised by the user or the user should use evidence already assessed rigorously by a competent and respected body. Otherwise it would not be the conscientious, explicit and judicious use of current best evidence. EBM can not be practised in isolation. Locally conducted research and continuous audit should be essential accompaniments of EBM. However, I agree with the authors that rejecting scientific research and EBM in toto as frivolous would deny the patients access to effective treatment and care.

\section{References}

1. Karunatilake H, Mendis ASV. Evidence besed medicine. Ceylon Medical Journal 2002; 47: 75-6.

2. Egger M, Smith GD, Steren JAC. Uses and abuses of metaanalysis. Clinical Medicine. Journal of the Royal College of Physicians of London 2001; 1: 478-84.

3. Crombie IK. Appraising review papers. In: The pocket guide to critical appraisal: A handbook for health care professionals. 1st ed. BMJ Publishing Group 1996: 56-62.

4. Guyatt GH, Sackett DL, Cook DJ. How to use an article about therapy or prevention. What were the results and will they help me in caring for my patients? Journal of the American Medical Association 1994; 271: 59-63.

Anuruddha Abeygunasekera, Urological Surgeon, Teaching Hospital, Colombo North.email: amabey@ sltnet.lk 